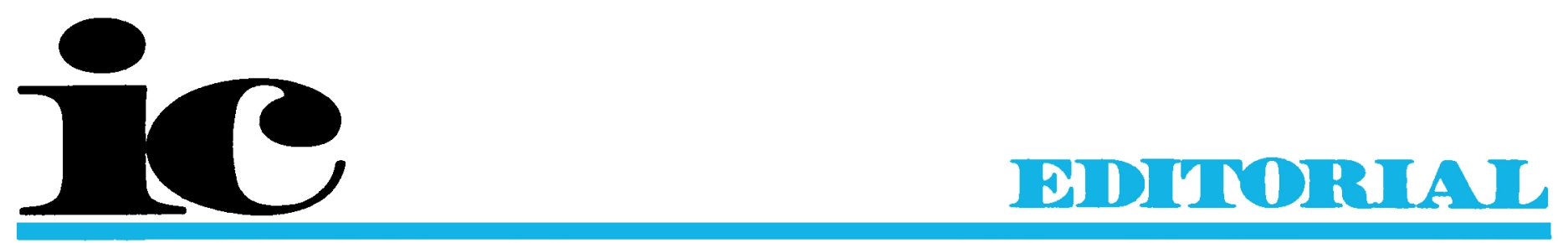

INIECTION CONTROL

\title{
Why SHEA?
}

The fledgling Society for Hospital Epidemiologists of America (SHEA), not quite three years old, is still defining its membership, goals, and relationship to the rest of the infection control community. SHEA was founded by a relatively small group of physicians who met at the 1980 Interscience Conference on Antimicrobial Agents and Chemotherapy (ICAAC). The venue of this first meeting is significant because it selected a core membership of infectious disease specialists who regularly attend national conferences. It is appropriate to consider how these infectious disease specialists became involved in infection control and why they decided to join a new society rather than rely on their membership in other organizations, such as the Infectious Diseases Society of America (IDSA), Association of Practitioners in Infection Control (APIC), or American Society for Microbiology (ASM), to meet their professional needs. It is even more important to consider whether SHEA, founded as it was by academically-oriented specialists, is relevant to other physicians who have infection control responsibilities in the nation's hospitals. Many of these individuals were not trained specifically in infectious diseases and do not have academic aspirations, yet some have joined SHEA, which now has a membership of more than 300 . Has the Society met their expectations? Can it continue to broaden its appeal?

A full understanding of the genesis of SHEA requires an historical perspective. SHEA is new, but the profession of infection control as we know it today is only a few years older. Infection control has undergone a revolution for which we were largely unprepared. Until very recently, few hospitals had a designated physician whose major responsibilities included nosocomial infection control. The vast majority of institutions did not even have a formal program for detecting and documenting nosocomial

Address reprint requests to Donald A. Goldmann, MD, Children's Hospital Medical Cienter. 300 Longuood Avenue, Boston, MA 02115. infections. Most infectious diseases specialists had only a passing interest in infection control issues, and research was generally confined to the investigation of nosocomial infection epidemics. Only a handful of pioneering investigators (such as Maxwell Finland) attempted to systematically document the patterns and trends of hospitalacquired infections.

Despite these modest beginnings, interest in nosocomial infections grew quickly, and in 1970 the First International Conference on Nosocomial Infections was convened. It was fitting that this conference was held at the Centers for Disease Control since the Hospital Infections Branch (then a mere Section) had already assumed leadership in the field. Most of the participants in that First International Conference concentrated on defining the magnitude of the nosocomial infection problem and describing the factors which seemed to be important in the pathogenesis of specific categories of infection (for example, the association of inhalation therapy with nosocomial gram-negative bacillary pneumonia). The role of environmental contamination was deemphasized, and routine environmental culturing was discouraged. The emerging threat of antibiotic resistance was noted. The special problems of immunocompromised patients were described. Rereading the proceedings of the First International Conference today, one is struck by the perspicacity of the participants who recognized the impact of nosocomial infections and stressed the need for infection control research. They set the infection control agenda for the following decade.

The infection control field has grown at a phenomenal rate since the First International Conference. A number of factors have been responsible for this amazing burst of activity. The Conference itself generated interest and concern. The massive nationwide epiclemic of intravenous fluid-associated septicemia in 1970), followed by reports of numerous smaller outbreaks, highlighted the importance of device-related nosocomial infections and 
dramatized the need for nosocomial infection surveillance and control programs in individual hospitals as well as at the national level. Graduates of CDC spread the word, and the CDC itself became even more active, offering infection control training courses and outbreak consultation and expanding its surveillance activities through the National Nosocomial Infections Study (NNIS). APIC was founded and provided professional support for the growing number of nurses and other health professionals who were entering the field.

Perhaps the greatest stimulus to the expansion of the infection control profession came from the Joint Commission on Accreditation of Hospitals (JCAH). To comply with the comprehensive recommendations promulgated by JCAH in 1976, hospitals rushed to establish formal infection control programs. Those institutions which took a casual approaches to the JCAH guidelines soon encountered the stern admonition of a disapproving surveyor. Clearly, compliance with the infection control standards was a high JCAH priority. The many hospitals that were faced with the task of building an infection control program from scratch quickly found that there were not enough available trained infection control practitioners. Only recently has the supply of trained practitioners begun to catch up with demand.

Most infection control practitioners relate to the medical staff in concert with a physician, usually the chairman of the infection control committee. Ideally, the infection control physician and practitioner should complement each other, with the physician supplying the expertise in infectious diseases, microbiology, and epidemiology and the practitioner emphasizing surveillance, control, and management techniques required to make the program work. The practitioner and physician should function as a team, with each member becoming increasingly familiar with the special skills of the other and ultimately developing new and creative approaches to the detection and control of infections in the hospital.

Many of the practitioners who read this editorial will immediately conclude that this utopian scenario does not apply to their program. Unfortunately, the background and training of most physicians who chair infection control committees have not prepared them for this new and demanding role. In part because the discipline is so young, the directors of most infectious disease training programs are themselves largely unskilled in infection control and tend not to teach it. Other directors may give a low priority to the study of infection control because they do not yet recognize that it requires unique skills and has vast academic potential. Even if a chief of an infectious diseases program wanted to provide training in infection control, funding for such fellowship positions has been extremely limited. The National Institutes of Health (NIH) have not provided training grants for infection control, and only a few investigators have received NIH grants to study nosocomial infections. The pharmaceutical industry subsidizes extensive research on antibiotics designed to treat nosocomial infections but has shown little interest in infection control research and training. (A notable exception is the recent announcement of a nosocomial infection research fellowship to be sponsored jointly by the National Foundation for Infectious Diseases and Beecham Laboratories.) In addition to not having received formal training in infection control and hospital epidemiology, most infectious disease trainees have not attended infection control committee meetings or participated in surveillance activities or outbreak investigations. Few have studied biostatistics or worked at a clinical microbiology laboratory bench. Even graduates of CDC, who at least have received training in statistics and epidemiology, are novices when it comes to other practical aspects of hospital infection control. If these infectious disease physicians have been inadequately trained in the basics of infection control, it is certainly understandable that the many surgeons and pathologists who chair infection control committees have not received this specialized training during their residencies.

Despite their lack of training and experience in infection control, recent graduates of infectious disease fellowship programs are often asked to accept responsibility for infection control by the hospitals in which they wish to practice. Therefore, they must immediately begin to learn their trade "on the job"-a difficult task at best. Although some physicians regard infection control as the burdensome price of a secure place on the medical staff, most enthusiastically accept the challenges of this fascinating profession. I cannot emphasize strongly enough that the vast majority of hospital epidemiologists I have met are bright, highly motivated, and dedicated. They find infection control challenging and exciting, are aware of the deficiencies in their training, and are eager to learn. They share a sense of insecurity about their new roles. They are acutely aware that to be $\mathbf{4 0}$ years old is to be a "senior" member of their very young profession. They realize that the quality and quantity of infection control research are suboptimal and that equality in the academic infectious diseases community has not yet been fully attained. They recognize that their positions are in part a creation of $\mathrm{JCAH}$ and that they are all vulnerable in a period of severe retrenchment in medical care. The Study on the Efficacy of Infection Control (SENIC) demonstrated the value of nosocomial infection surveillance and control programs, but not of hospital epidemiologists.

What, then, is the mission of SHEA? Although SHEA was founded by a small group of hospital epidemiologists drawn principally from the infectious diseases divisions of university hospitals, it has been clear from the start that SHEA is not just a club of academically-oriented chums. Its most important goal is to foster those activities that will improve the medical care of patients through the prevention and control of nosocomial infections. It is also a support group dedicated to improving the professional standing of hospital epidemiologists. Since most hospital epidemiologists work in relative isolation, enhancing communication and sharing resources are high priorities. To this end, a newsletter has been established and a membership list published. An annual business meeting and luncheon are now held at ICAAC, a convenient but not optimal setting since many members do not attend this meeting. Since the need for education is so great, SHEA is exploring participation in APIC-initiated training programs for infection control teams. SHEA has also 
contacted the Accreditation Committee on Graduate Medical Education to press for increased emphasis on infection control in infectious diseases training programs. To facilitate dissemination of new information, SHEA is making a major effort to establish infection control seminars and scientific sessions at national meetings. Last year SHEA members participated in infection control seminars at the annual meetings of ICAAC, APIC, ASM (through the Nosocomial Infections Division of ASM), the Society of Epidemiologic Research (SER), and the College of American Pathologists (CAP), and the Society is endeavoring to ensure a continued presence at these meetings.

SHEA members are, for the most part, busy overcommitted physicians. Moreover the total membership is relatively small. Therefore, the Society cannot undertake vast projects on its own and relies heavily on working through existing channels and establishing strong liaisons with organizations which share an interest in infection control. Liaisons have been established with APIC, ASM, SER, CDC, and the American Hospital Association (AHA). Because so many infection control committee chairpeople are surgeons and pathologists, liaisons with the Surgical Infections Society and the American Society of Clinical Pathologists (ASCP) are being explored. Since the activities of hospital epidemiologists are so frequently influenced by guidelines, recommendations, and regulations promulgated by others, SHEA has vigorously offered input into decisions involving infection control. For example, SHEA representatives participated in drafting the Immunization Practices Advisory Committee
(ACIP) hepatitis B vaccine guidelines for hospital personnel. SHEA has also established a liaison with JCAH in preparation for the anticipated revision of the infection control standards.

These are heady times for SHEA. The first three years have been surprisingly fruitful for such a young organization. The membership is growing, yet SHEA has little reason to be cocky. The list of accomplishments is short and the agenda long, and it remains to be seen whether the Society's early initiatives can be sustained. SHEA has not yet found a way to maximize participation by epidemiologists in community hospitals, and little effort has been made to determine if SHEA is meeting their needs. It has not yet been decided whether the Society should recruit the many surgeons and pathologists who serve as infection control committee chairpersons. The relationship with APIC is sound and productive but needs further nurturing. But in spite of these few words of caution, those of us who have been a part of SHEA during its formative years are enthusiastic about its future. What we need now is the advice and help of the physicians who are responsible for infection control in the nation's hospitals, whether SHEA members or not.

\author{
Donald A. Goldmann, MD \\ Division of Infectious Diseases \\ Children's Hospital Medical Center \\ and Harvard Medical School \\ Boston, Massachusetts
}

